\title{
Systems Engineering Education Development (SEED) Case Study
}

\author{
Thirteenth Annual International Symposium of the \\ International Council On Systems Engineering (INCOSE)
}

29 June to 3 July 2003

\author{
Thomas C. Bagg, III \\ QSS Group, Inc. \\ 7404 Executive Place, Suite 400 \\ Seabrook, MD 20706 \\ 301-867-0063 \\ tbagg@qssmeds.com \\ Mark D. Brumfield \\ Acting Division Chief for the Systems \\ Engineering and Advanced Concepts Division, \\ NASA Goddard Space Flight Center \\ Mailstop 530 \\ Greenbelt, MD 20771 \\ Donald E. Jamison \\ NASA Goddard Space Flight Center \\ Mailstop 581 \\ Greenbelt, MD 20771
}

\author{
Raymond L. Granata \\ QSS Group, Inc. \\ 7404 Executive Place, Suite 400 \\ Seabrook, MD 20706 \\ 301-867-0143 \\ rgranata@qssmeds.com \\ Carolyn A. Casey \\ NASA Goddard Space Flight Center \\ Mailstop 501 \\ Greenbelt, MD 20771
}

\begin{abstract}
The Systems Engineering Development Program (SEED) was initiated to help Goddard resolve a Systems Engineering skill shortage. The chronology of events and the experiences of the pilot program are outlined to describe the development of the present program. The program goals are included in order to give a focus on what the developers saw as the program drivers. Lessons learned from a pilot program were incorporated into the present program. This program is constantly learning from its past efforts and looks for continuous improvement. We list several future ideas for improvement and change.
\end{abstract}

\section{SEED Program Overview}

The Systems Engineering Education Development Program (SEED) is designed to recruit incumbent discipline engineers and train them to become Systems Engineers in the National Aeronautics and Space Administration (NASA) Goddard Spaceflight Center (GSFC) environment. The training includes a combination of classroom training, rotational assignments, mentoring, and leadership coaching.(See Figure 1). 


\section{Figure 1 SEED Program Path}

SEED is designed as a two-phase program Phase I provides an overview of the engineering systems life cycle and introductory experiences in multiple technical disciplines. Phase II provides in-depth assignments to fill specific experience gaps and leads to graduation. Upon graduation the Program Administrator will assist the Mentee in the selection of a permanent assignment.

The formal training program incorporates subjects in multiple technical disciplines, leadership roles, human interaction, and management training. The SEED Program schedules inhouse workshops, (technical and non-technical), encourages attendance at local seminars, formal class work (NASA or University offerings), and rotational assignments supporting disciplines. Rotational assignments are with active projects at GSFC.

Progress within the SEED Program is established by having quarterly progress reviews. The SEED Program evaluates the Mentees, the Mentors, all program areas of the SEED to identify what's right and what's wrong, and the effectiveness of rotational assignments and formal classes. These reviews are provided to the Program Manager and the Advisory Board.

\section{SEED Purpose/Background}

NASA's GSFC, like other technical organizations, is experiencing several manpower problems. Many highly qualified employees are retiring from hard to fill positions and this creates a shift of focus in our skill needs. GSFC is recognizing that it can train talented junior engineers to become Systems Engineers. The SEED Program was designed to provide GSFC with a trained Systems Engineering work force to replace the present Systems Engineers when they retire.

This program is one of GSFC's responses to The NASA Strategic Plan for 2000, which stated:

"Our human capital investment strategy begins with the recognition that employees are our most important resource. We must align our management of that resource to best achieve our strategic goals and objectives. As part of that effort we are working to attain and retain a world-class workforce with the necessary skills and competencies. We will also encourage continual learning, including an emphasis on technical training, change management, leadership development, and career management.

To ensure that we retain a strong skilled, creative, and effective human resource capability, we will periodically assess the effectiveness of our human capital policies, practices, and tools. Our human capital planning efforts strive to anticipate future changes and workforce issues as NASA continues to move from operations toward more research and development work."

\section{SEED Goals}

Systems Engineering involves an interdisciplinary approach, which aims to capture stakeholder needs and objectives and to transform these into a balanced, holistic, life-cycle system. This approach aims to satisfy the stakeholders' minimum requirements, and to optimize the overall 
project and system effectiveness.

Stakeholder measures of effectiveness include time to completion, program costs, value added, measures of user benefits (e.g., product quality, human factors, science capabilities), and political benefits.

Systems Engineering can therefore be characterized as a set of principles supported by processes, to deliver maximum benefits to stakeholders by successfully exploiting technology.

The SEED Program encompasses the following goals to develop Systems Engineers:

- Educate mid-level discipline engineers to become competent Systems Engineers.

- Provide GSFC with highly trained personnel skilled in the development of space systems who can meet critical systems engineering needs.

- Provide exposure to new and different perspectives on systems engineering issues.

- Develop approaches for recognizing and defining problems as well as potential solutions.

- Broaden individual skills to enhance performance as a Systems Engineer.

- Provide experience to support strategic systems planning.

- Prepare systems engineers for leadership responsibilities.

\section{Development Chronology and History}

Development Overview GSFC recognized its Systems Engineering skills need in mid 1999. A committee was formed to recommend a solution to this need. The committee recommendation resulted in a pilot training program. The pilot class consisted of 4 Mentees and 3 Mentors. A revised SEED Program was approved in June 2001. The present program is an enhancement of the pilot concept with changes based on a lessons learned study.

Team. The first step in developing the present program was to assemble a team with a broad range of skills. The team consisted of up to 10 players from various organizations such as technical training, personnel development, Systems Engineering, and the Engineering Directorates. The next step was to interview all members of the pilot program and develop a list of Lessons Learned. The team realized that the Pilot Program was initiated as a trial program and these interviews could yield valuable lessons. The third step was to organize the SEED development into logical elements (training, technical, mentoring, administration, rotational assignments, and formal classes) and give the team members specific tasks.

Pilot. All of the Mentees selected for the pilot class were experienced senior engineers who had expertise in a specific discipline. Training was provided to develop them into Systems Engineers. The Mentors selected for the pilot program also had little or no training for mentoring.

Lessons Learned: The lessons learned survey provided the team with 4 major issues.

1. The SEED Organization must provide quality support to this program.

2. The program needed a more structured approach for dealing with Mentee rotational assignments and classroom training.

3. Dual track training program (Mission or Instrument SE) in the pilot program restricted curriculum options and assignment flexibility.

4. The SEED Program must have direct control of all allocated resources so that it can easily and quickly implement training opportunities. 
The following elements are the revisions incorporated into the SEED Program to address the lessons learned.

1. Increased accountability of the activities within the SEED Program by adding structure to the processes and providing metrics for management. These organizational changes were made:

- The responsibilities of each SEED Organizational position were clearly defined. (See Organization and Responsibilities.)

- A new position, Leadership and Career Development Coordinator, was established to assist in the training and career needs.

- Delineated and increased the responsibilities of the Advisory Board.

- Elevated the SEED Program Administrators responsibilities as his top priority job

2. Negotiated contracts for each rotational assignment defining specific goals and products, developed Individual Development Plans (IDP) for each Mentee, required quarterly reviews of each Mentee's progress, provided training to Mentors, rewarded Mentors for doing a good job, and documented the program with a plan and a handbook. These elements not only serve the present class but also will assist in orientation of future classes.

3. Established a single-track program allowing Mentees to be educated in both mission and instrument disciplines by merging the original dual track process. This provided insight to both disciplines and gives the Mentees the chance to select their preference after graduation.

4. Still negotiating with upper management for more direct control of all allocated resources so that SEED can easily and quickly implement training opportunities. Mentees have been officially detailed to SEED Program Manager to provide isolation from their parent organization.

\section{Current Class}

Mentee Selection. In August 2001 an announcement for a new class of Mentees was released. Candidates are eligible from all technical areas of GSFC allowing employees to expand their expertise and to provide SEED with a larger quantity of possible candidates. The SEED program received 20 responses. These were evaluated and 10 applicants were determined to meet the minimum requirements. A selection panel separately interviewed these 10 applicants. Each candidate was asked questions, which could provide insights for the panel on their technical abilities, leadership qualities, oral skills, and an understanding of which ones had a broad view for solving problems. The SEED Program had considered a class of 4 Mentees. The interview process demonstrated that 6 candidates displayed the technical and leadership qualities that SEED was looking for. All 6 candidates were accepted into the program. The first class started in January 2002. This class will participate for 2 to 3 years.

SEED will have an annual call for new Mentors and new Mentees to support GSFC's need for good Systems Engineers. Each year the class size will be assessed but the present class of 6 Mentees seems to be the level that can be supported. When a 3-year cycle is complete the SEED Program may have from 12 to 18 active participants.

Mentor Selection. Concurrent with the announcement for Mentees, the SEED Program was advertising for Mentor applicants. Mentor candidates were selected from experienced Systems Engineers who volunteered to support the SEED Program. Mentor criteria include a high level 
of experience in the discipline areas needed by the Mentees, organizational trust, ability to communicate with junior engineers, and a willingness to support the SEED Program.

Mentor/Mentee matching. In December 01 and January 02 the SEED Program held sessions where an informal environment was provided to allow all SEED participants to get to know one another. The Team members observed the interactions to assist in developing Mentor/Mentee pairing. Also, each Mentor and Mentee was asked to list and rank their top three choices for a partnership. This process was successful in establishing the 6 Mentor/Mentee pairs. After 8 months of activities we have seen positive results among the pairs. The SEED Team continues to schedule monthly meetings or workshops where all parties are invited to participate in group activities and further develop interpersonal relationships. This will be useful in their careers as a valuable 'Shadow' organization.

Rotational assignments. Rotational assignments are within a flight project or mission area, which provides hands on training for the needed discipline. A Discipline Mentor supports the Mentee during this assignment. The Discipline Mentor has responsibility to the project and is willing to relate technical experiences to the Mentee. Each assignment will have a contract, which states goals, duration, and deliverables.

IDP's. The SEED Program generated Individual Development Plans (IDP) for each Mentee. This IDP incorporates the experiences of the Mentee, the history of the Mentees provided by their supervisor, input from the SEED Team and the Mentees goals.

- Each Mentee's experience is compared against a set of core Systems Engineering competencies to identify gaps.

- An Individual Development Plan (IDP) or roadmap is developed based on the gap analysis.

- Rotational assignments are based on the gap analysis to provide needed experiences. Optional assignments are available if time allows.

- Rotational assignments are under the direction of a senior level Discipline Mentor.

Leadership Training. The SEED organization realized that the Mentees possessed technical talents but as Systems Engineers they must also have leadership qualities. The program has put emphasis on this skill and requires each Mentee to take leadership training. This training involves formal classes, workshops, and individual coaching. This training is offered to all SEED participants including the Management Team.

\section{Organization and Responsibilities}

The SEED organization consists of a Program Manager, a Program Administrator, a Leadership and Career Development Coordinator, and an Advisory Board. (SEED Organization, Figure 2)

Principle duties of the program manager are to oversee the program, implement policy, chair the advisory board lead the Selection Committee and manage the budget.

Major duties of the Program Administrator are providing program oversight, administrative support for the Mentors and Mentees, administering the IDP process, providing reports for the Program Manager and the Advisory Board, maintaining the course curriculum, and recommending Mentees for graduation and Mentors for awards. 


\section{SEED Organization, Figure 2}

Duties of the Leadership and Career Development Coordinator are counselling the Mentees, supporting their Supervisors and Mentors, supporting the IDP process, negotiating rotational assignments, coaching the Mentors, participating in quarterly and annual Mentee reviews, assisting in the development of curriculum and arranging leadership development training.

The SEED Advisory Board acts as the Mentee selection committee, resolves program issues, performs annual SEED Program reviews, approves successful candidates for graduation, and approves recommendations for Mentor awards.

\section{Mentors role:}

- Making a commitment to teach and guide the Mentee through their participation in SEED.

- Acting as a sounding board for Mentee's ideas, goals and aspirations, and instilling an impetus for action toward achieving them

- Providing advice to the Mentee on matters relating to his/her career development

- Identifying developmental objectives that are specific, measurable, achievable and compatible with skill competencies

- Being available to discuss the problems and concerns of the Mentee as they occur by sharing their experiences

- Supporting the Mentee in establishing a network of human resources at all position levels

- Providing feedback to the Mentee regarding his/her strengths and developmental needs

\section{Mentees responsibilities:}

- Acknowledging that the development of their career can be achieved through a process of intentional planned experiences and assignments

- Being open to new discoveries and possibilities that would result in a higher level of potential for them and the organization

- Being receptive to learning and developing a learning relationship with a Mentor(s)

- Discussing ideas, goals, aspirations, and plans for action with the mentor and the supervisor.

- Accepting responsibility for accomplishment of the IDP

- Being willing to discuss development problems and concerns as they occur with your Mentor

- Seeking feedback from your mentor and others regarding your strengths and additional developmental needs

Future: Expand program to include at least 12 Mentees. This will require that SEED management investigate the attrition rate of systems engineers at GSFC and to determine the number of systems engineers on current projects in order to forecast systems engineering resource needs.

Share knowledge and resources with other organizations that have Mentoring programs within NASA

Couple this program with the NASA Headquarters education program.

Establish an alliance with Local Universities

- Familiarize them with hands-on experiences and working in the GSFC culture. 
- Interchange Mentees, Students, and Professors.

- Coordinate with a formal Certificate Masters or degree program.

\section{Documentation}

Program Plan: A SEED Program Plan was developed to provide Management with a document that describes the development activities of the SEED Program.

Handbook: A SEED Handbook documents the program and serves as an operations manual. This handbook identifies the Mentee selection process, IDP process, Mentee and Mentor criteria. It also provides a description of the mentoring process, the responsibilities of the Mentee, and a list of courses and their content.

Brochure: SEED has a tri-fold marketing brochure to advertise and list the key aspect of the program.

Presentation: The SEED presentation is the basis for briefing other organizations on the SEED program.

\section{Summary/Conclusions}

The selection process yielded six very good and enthusiastic Mentees. They all have proven to be self-starters, quickly familiarizing themselves with the program, looking into project assignments, and enrolling into formal classes. This energy has relieved the SEED Team of some of its administrative activities.

Call for volunteers to serve as Mentors resulted in a rich find of senior level Systems Engineers who were not only talented engineers but also good and willing Mentors.

All GSFC projects have a need for systems engineering support and prove to be a good source of assignments for the Mentees. Each assignment has served as an arena to learn a particular discipline and some of the basics of the system life-cycle processes. Project managers, after some initial hesitancy, are now requesting SEED participants to serve rotational assignments on their projects.

The administration of SEED may seem taxing but that was done intentionally in order to relieve the Mentors and Mentees of as much paperwork as possible. This allows them to devote a majority of their time to technical support, and learning and teaching issues.

GSFC management is cooperating with this program by allowing the Team the freedom to move across organizational boundaries for assignments, announcing results at management meetings, providing budgets and encouragement to continue the "good work".

\section{REFERENCES}

NASA, "NASA Strategic Plan for 2000", National Aeronautics and Space Administration, http://www.hq. nasa.gov/office/codez/plans.html

NASA GSFC, Code 530 "Systems Engineering Education Development (SEED) Program Handbook", August 20, 2002. 
NASA GSFC, Code 530 "Systems Engineering Education Development (SEED) Program Plan, DRAFT", May 29, 2002.

\section{BIOGRAPHIES}

Thomas C. Bagg, III is a Senior Systems Engineer at QSS Group, Inc. He has 25 years of experience in the development and testing of aerospace and defense systems. He was awarded the NASA Contractor Excellence Award in 2002 for his work developing the Systems Engineering Education Development (SEED) Program for NASA at the Goddard Space Flight Center. He is a member of the INCOSE Education and Research Technical Committee, the Space Systems Working Group, and served as Co-Chair of the INCOSE Telecommunications Working Group of the Systems Engineering Applications Technical Committee. He is a member of the INCOSE Chesapeake Chapter. He runs rocket launches for local schools and scout troops, and runs an annual Space Night at his local elementary school for educational outreach. Tom received his BA in Physics from Lafayette College, and his MS in Systems Management from Capitol College.

Raymond L. Granata is a systems engineer at QSS Group, Inc. He has 46 years of experience in the planning, development, integration, test, and operations of aerospace space systems. His last major task at NASA GSFC was as Program Administrator of the Systems Engineering Education Development (SEED) program. He served as Co-Chair of the INCOSE Space Systems Working Group of the Systems Engineering Applications Technical Committee, and he is a member of the INCOSE Chesapeake Chapter. Ray received his BS in Physics from University of Portland, and did graduate work in Physics at University of Chicago.

Mark Brumfield is the Acting Division Chief for the Systems Engineering and Advanced Concepts Division (SEACD) at NASA's Goddard Space Flight Center. The SEACD is responsible for end-to-end Mission Systems Engineering for all of the Goddard missions. Mark has 16 years experience in computer engineering, missile dynamic modeling, robotics, systems engineering, instrument systems engineering, project management, and organization management. He was a systems engineer for the instrument responsible for correcting the flawed mirror for the Hubble Space Telescope (COSTAR). He was the Instrument Systems Manager for the Polar Orbiting Environmental Satellite (POES) Program. As chief of the SEACD, he is now the Program Manger for the Systems Engineering Education Development (SEED) Program. Mark received his BS in Mechanical Engineering from Purdue University and his M.S. in Mechanical Engineering specializing in both robotics and aerospace from The George Washington University.

Donald E. Jamison is the Program Administrator of the Systems Engineering Education Development (SEED) Program. He has nearly 45 years of experience in information technology. He has participated and managed the development of hardware and software for space data processing, communications, and command and control systems for the government and industry. He has bachelor degrees in electrical engineering and business, and masters degrees with concentrations in operations research, business and computer systems. He is a member of INCOSE. 